\title{
XLIX. Note on Mr. E. H. Hall's Experiments on the "action of magnetism on a permanent electric current"
}

\section{J. Hopkinson F.R.S.}

To cite this article: J. Hopkinson F.R.S. (1880) XLIX. Note on Mr. E. H. Hall's Experiments on the "action of magnetism on a permanent electric current", Philosophical Magazine Series 5, 10:64, 430-431, DOI: $10.1080 / 14786448008626952$

To link to this article: http://dx.doi.org/10.1080/14786448008626952

曲 Published online: 08 May 2009.

Submit your article to this journal $[\pi$

Џll Article views: 4

Q View related articles ¿ 
properly protected. There are many cases where the pinnacles of the same turret of a church have been struck where one has had a rod attached to it; but it is clear that the other pinnacles were outside the cone; and therefore, for protection, each pinnacle should have had its own rod. It is evident also that every prominent point of a building should have its rod, and that the higher the rod the greater is the space protected.

XLIX. Note on Mr. E. H. Hall's" Experiments on the "Action of Magnetism on a permanent Electric Current." By J. HOPEINSON, F.R.S. $\uparrow^{\dagger}$

TF X, Y, Z be the components of electromotive foree, and $\mathcal{L} u, v, w$ the components of current at any point, in any body condncting electricity, we have the equations

$$
\left.\begin{array}{l}
\mathrm{X}=\mathrm{R}_{1} u+\mathrm{S}_{3} v+\mathrm{S}_{2} w-\mathrm{T} v, \\
\mathrm{Y}=\mathrm{S}_{3} u+\mathrm{R}_{2} v+\mathrm{S}_{1} w+\mathrm{T} u, \\
\mathrm{Z}=\mathrm{S}_{2} u+\mathrm{S}_{1} v+\mathrm{R}_{3} w,
\end{array}\right\}
$$

where $R_{1}, R_{2}, R_{3}, S_{1}, S_{2}, S_{3}$, T are constants for the substance under its then circumstances (vide Maxwell's 'Electricity, vol. i. p. 349).

After obtaining these equations, Maxwell goes on to say:"It appears from these equations that we may consider the electromotive force as the resultant of two forces, one of them depending on the coefficients $\mathrm{R}$ and $\mathrm{S}$, and the other depending on $T$ alone. The part depending on $R$ and $S$ is related to the current in the same way that the perpendicular on the tangent plane of an ellipsoid is related to the radius vector. The other part, depending on $T$, is equal to the product of $T$ into the resolved part of the current perpendicular to the axis of $T$; and its direction is perpendicular to $T$ and to the current, being always in the direction in which the resolved part of the current would lie if turned $90^{\circ}$ in the positive direction round T.

"Considering the current and $\mathrm{T}$ as vectors, the part of the electromotive force due to $\mathrm{T}$ is the vector part of the product $\mathrm{T} \times$ current.

"The coefficient $T$ may be called the rotatory coefficient. We have reason to believe that it does not exist in any known substance. It should be found, if any where, in magnets which have a polarization in one direction, probably due to a rotational phenomenon in the substance."

* Phil. Mag. March and November 1880.

$\dagger$ Communicated by the Author. 
Does not the " rotatory coefficient" of resistance completely express the important facts discovered by Mr. Hall? Instead of expressing these facts by saying that there is a direct action of a magnetic field on a steady current as distinguished from the body conducting the current, may we not with equal convenience express them by saying that the effect of a magnetic field on a conductor is to change its coefficients of resistance in such wise that the electromotive force is no longer a selfconjugate-linear-vector function of the current?

L. On the Number of Electrostatic Units in the Electromagnetic Unit. $B y$ R. SHIDA, M.E., Imperial College of Engineering, Tokio, Japan*.

TWHE object of this paper is to explain measurements made 1 during the month of July last for an evaluation of " $v$," the number of electrostatic units in the electromagnetic unit -a question which has much engaged the attention of the British Association. We can evaluate " $v$ " by determining the electrostatic and also the electromagnetic measure of any one of the following terms-Electromotive Force, Resistance, Current, Quantity, and Capacity. It is the first of these terms that I measured in the two systems of units; and the E.M.F. was that of Sir William Thomson's gravity Daniell, which is very constant. The question divides itself into two parts:-

(A) Absolute Electrostatic Measurement of the E.M.F.

This measurement was made by means of Sir William Thomson's absolute electrometer. It is not easy to explain shortly how the electrostatic measurement is made by this instrument; but, briefly speaking, it is as follows:-Imagine a circular disk suspended by springs in a horizontal plane inside the aperture of another larger plate in the same plane, with a continuous plate below and parallel to them. The force of electrical attraction of the continuous plate on the disk is compared with the gravitating force of a known weight. To effect this, any electrical influence having been entirely removed, a known weight is put on the disk, which is then raised by means of a micrometer-screw until it comes to its original position; and then the weight is taken away, allowing electrical force to act when the continuous plate is adjusted by the aid of another micrometer-screw, to bring the disk to the same position as before. A full account of the instrument will be found in Sir William Thomson's Report on Electro-

* Communicated by Sir William Thomson, having been read in Section A of the Meeting of the British Association at Swansea. 